\title{
Consequences of microaggresion, macroagression, and mega-aggression from the public health perspective
}

\author{
Elena N. Naumova ${ }^{1}$
}

Accepted: 9 December 2021 / Published online: 4 January 2022

(C) The Author(s), under exclusive licence to Springer Nature Limited 2021

\begin{abstract}
Along with large calamities like natural disasters, environmental degradation, and pandemics fueled by viral mutation and social discourse, aggression now brewing comes on various scales: micro-, macro-, and mega-aggression. While mega-aggression episodes spill over to large-scale conflicts for economic or political gains, macroaggression occurs at a structural level intended to exclude targeted groups either by action or omission. And microaggression refers to commonplace daily verbal, behavioral, or environmental slights toward stigmatized or culturally marginalized groups. At any scale, aggression dramatically reduces the ability of public health professionals to prevent, respond to, and recover from any shock. These shocks could stem or result from various hazards and dangers, from military conflicts in war-prone areas, radioactive exposures due to man-made and natural disasters, guns in hands of mentally ill, or bullying on school playgrounds.
\end{abstract}

For public health professionals, it means we need a much broader prevention framework to address the whole spectrum of aggression. This framework should include critical areas of occupational health, mental health, and social wellbeingalong with recognizing the drivers and consequences of microaggresion, macroagression, and mega-aggression.

In early 1980s, I learned about what was then a new movement of the International Physicians for the Prevention of Nuclear War (IPPNW). At that time, I was a graduate student interested in modeling the transmission of infectious outbreaks at a local and global scales. The IPPNW warned that a nuclear war would be the final epidemic: with no cure, no meaningful medical response, and no rapid recovery. For me it was an eye-opening message. The medical and environmental consequences of nuclear warfare contained a profound revelation of finitude and fragility of the human race. There was no doubt that preventing populations from entering into conflicts resulting in nuclear war and radioactive exposure at sites of nuclear weapons testing and production is a major part of the public health agenda.

Elena N. Naumova

elena.naumova@tufts.edu

1 Friedman School of Nutrition Science and Policy, Tufts University, Boston, USA 
The efforts of IPPNW in the 1980s to educate health professionals, political leaders, and the public united physicians across the Cold War divide and drew widespread attention and recognition. IPPNW received the UNESCO Peace Education Prize in 1984 and the Nobel Peace Prize in 1985. One year after, the Chernobyl nuclear disaster shocked the world. I remember worrying about friends and colleagues participating in clean-up or caring for those whom the Chernobyl leak exposed to radiation. The painful consequences of human mishaps in handling dangerous radioactive material are as clear and present today as they were then. There is also no doubt that preventing a population health calamity from a nuclear disaster and exposures at workplaces, at homes, or near sites of storing radioactive material is a crucial focus for public health.

With the existing arsenal of firearms, nuclear weapons, and other weapons of mass destruction, humans steadily increase chances for our own extinction. Thus, with an invitation from IPPNW to attend their press briefing in January 2021, I immediately asked how JPHP could again help to spread the warning call. In 2007, the Journal published a Special Section on armed conflicts and their challenges to public health. This first JPHP issue of 2022 features a review by Dr. Tilman Ruff, Co-President of the IPPNW, and Founding Chair of the International Campaign to Abolish Nuclear Weapons. He somberly reminds us of the continuing danger and potential consequences of a nuclear war. He points out that fewer than $2 \%$ of nuclear weapons in arsenals today, if exploded on cities, would abruptly cause ice age conditions, putting over 2 billion people at risk of starvation. His review also delivers a strong message to health professionals that effective evidence-based advocacy by scientific community has been, and can again be, instrumental for constraining and reversing the nuclear arms race [1].

This issue also features a Viewpoint on the inability of the USA to control guns [2]. Even with broad public consensus on the need to prohibit individuals with mental illness from possessing firearms and with staggering statistics on mass shootings in schools, churches, and playgrounds, policymakers and elected officials repeatedly prove unable to develop rules for gun purchase, possession, and use. Proposals to expand the arsenal of public health tools to include national gun violence surveillance systems, registries, emergency gun removal programs deserve attention from all-the public, health professionals, researchers, and policymakers. We need these tools to measure the impact of national policies aiming to reduce the risk of gun violence. It will also help us to recognize how to deal with macroagression by dismantling structures that stigmatize individuals with mental illness and instead offering critical support. As the tobacco industry has been paying for the health problems it caused, the gun industry should cover public health programs that are urgently needed to quell gun violence.

In comparison to growing danger of nuclear weapons and firearms, common bullying among teens sounds like nothing. Driven by microaggression, something that might look benign and harmless could instead communicate hostile, derogatory, or negative attitudes toward stigmatized groups, intentionally or unintentionally. Supported by societal inequalities, both micro and macroaggressions give rise to distrust of authorities and professionals. Yet perhaps, this is where we have a chance to succeed. Given that weight-based bullying is one of the most prevalent forms of peer 
harassment carrying significant health-including mental health-consequences, anti-bullying legislation may offer a strategy worth testing [3].

Advocacy toward protecting minorities might yield highly desirable consequences. A simple example: by making public buildings wheelchair-accessible-for a relatively small fraction of population-we are helping anyone who might also benefit, like a parent with a stroller or an athlete recovering from an injury, thus reducing the hardship for many more. Mastering skills for identifying mutual benefits and common ground, skills of pervasion, and teambuilding are the tools of public health professionals.

- Could more of us learn how to listen and negotiate toward achieving common goals?

- How could more of us actively pursue a chance to respond assertively and build communal resilience?

There is a clear link across all scales of aggression from micro to macro to mega. The ways kids in playgrounds deal with bullies reflect what they learn from their surroundings - and, in turn, reflect the extent of societal polarization, discourse, and aggression. If they learn how to sort things out, there is a hope that they will be able to solve bigger problems. The ways public health professionals advocate for stigmatized teens, the mentally ill, workers in hazardous conditions, all reflect what they are capable of in changing the society, the playground rules.

Imagine that the human and natural resources directed at producing, testing, and upgrading weapons are used instead to make those playgrounds-the ones bullies aim to boss-better, smarter, and safer. Imagine a small fraction of the tremendous price countries expend in the arms race redirected to address the mental health crisis, to reach agreement on gun laws, to protect playgrounds from mass shootings, and to help victims of gun violence to heal. That is, imagine if efforts to build systems of destruction could be redirected to help communities to strive. If "operating an F-35 nuclear-capable combat aircraft for one hour costs as much as a nurse earns in a year" [1], how much could a $1 \%$ reduction in nuclear weapon spending or $10 \%$ of the profit from 11.5 million firearms manufactured in 2016 in the United States [4] alone support initiatives proposed by public health professionals?

The idea of comparing military hardware costs to public health expenditure is not new. The suggestions to redirect a fraction of the military budget to pay for robust and lasting public health programs have been floating through public discussions for a while. Yet, these proposals are not yielding the desirable actions and results. Expressing public health needs to address all forms of aggression in terms of expenditures for producing the tools of aggression could be an important step toward measuring our progress in protecting human health. A good place to start is to rethink our current priorities with respect to consequences of addressing and not addressing all forms of aggression.

- Could we develop a comprehensive and systematic approach to understanding the root cause of these public health problems and a mechanism to eradicate the roots in a comprehensive and systematic manner? 
- Could we build an accountability system where those who are profiting from fueling the aggression are paying for the consequences?

All forms of aggression are public health issues as are any other factors threatening wellbeing, especially when communities are in distress. In a resilient society, all forms of aggression are controlled, regulated, and mitigated. In a polarized society, episodes of microaggression and macroaggression each fuel the other, and episodes of macroaggression could escalate to the mega-aggression level rapidly. In the modern world, we should be able to recognize aggression in the communities we serve in a timely manner and be able to recognize when someone directs it toward us or others. We should learn the root causes, drivers, and triggers of aggression; learn how to address and mitigate short-term and long-term consequences of aggression and how to build resilience, resistance, immunity. Most of all, we should learn how to engage every person to become a public health advocate.

In March of 2015, 30 years after the Chernobyl disaster, I participated in the World Conference on Disaster Risk Reduction in Sendai, Japan, organized by the United Nations to commemorate the Fukushima's nuclear disaster followed by one of the most powerful tsunamis ever. This conference warned of a dangerous collision of climatic calamities with fragile and complex infrastructures. From a trip to Sendai's disasteraffected areas with student volunteers from Yellow Handkerchief Campaign, I kept my notes inspired by their stories:

In times of disasters, the old wounds reopen, and the new ones arrive. In our polarized world, it takes guts to treat each person with kindness and respect regardless of their intellectual capacity, physical appearance, social upbringing, skin color, mother tongue, religion, race, gender, or sexual orientation. In times when wounds are still open, it takes many hearts to help those who are hopeless, who are afraid to ask, who are refusing help. In times when wounds are healing, it takes many souls to keep scars from burning and help the healers. And even when the pain subsides, it takes brains to find a path to recover, restore, and rebuild in an inclusive way, so when a disaster strikes again, we don't repeat our old mistakes.

Elena N. Naumova, Editor-in-Chief

\section{References}

1. Ruff T. Ending nuclear weapons before they end us: current challenges and paths to avoiding a public health catastrophe. 2022;43(1).

2. Appel JM. Mental health and firearms: what is our trajectory in the United States? 2022;43(1).

3. Lessard LM, Watson RJ, Schacter HL, Wheldon CW, Puhl RM. Weight enumeration in United States anti-bullying laws: associations with rates and risks of weight-based bullying among sexual and gender minority adolescents. 2022;43(1).

4. Number of firearms manufactured in the U.S. from 1986 to 2019. https://www.statista.com/stati stics/215395/number-of-total-firearms-manufactured-in-the-us/. Accessed 16 Dec 2021.

Publisher's Note Springer Nature remains neutral with regard to jurisdictional claims in published maps and institutional affiliations. 